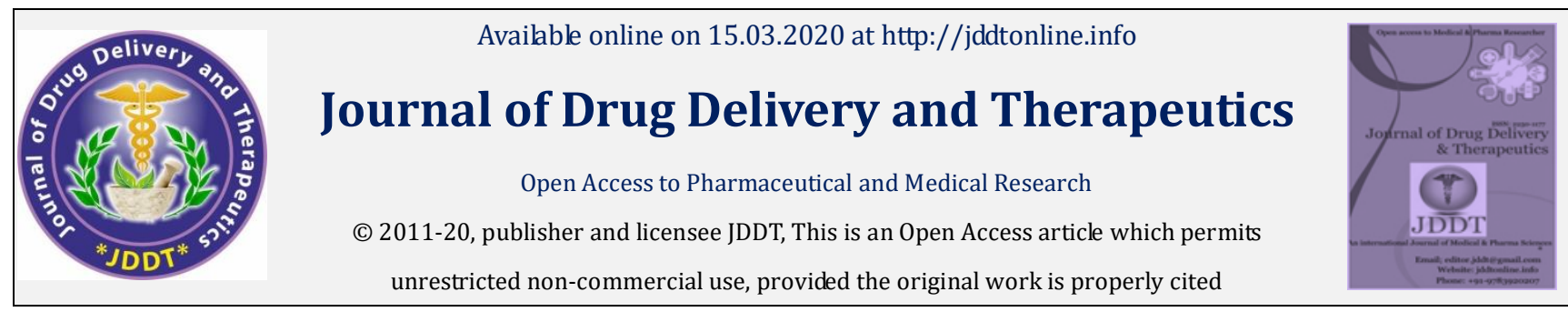

Open Access

Research Article

\title{
In-Vitro Antioxidant Activity and Total Phenolic Content of Ruta montana L.
}

\section{Extracts}

\section{Mounira Merghem*, Saliha Dahamna}

Laboratory of Phytotherapy Applied to Chronic Diseases, Department of biology and animal physiology, Faculty of Natural and Life Sciences, Ferhat Abbas University, Sétif, Algeria

\begin{abstract}
The aim of this study is to evaluate in vitro antioxidant activities of Ruta montana L. extracts. This activity was evaluated by three methods : DPPH (2, 2'-diphenyl- 1- picrylhydrazy), bleaching of $\beta$-carotene and chelation of ferrous iron. Results showed that ethyl acetate extract (EAE) represents the highest amount of total polyphenols, tannins and flavonoids with $257,1 \pm 0,703 \mu \mathrm{g}$ gallic acid equivalent/mg of extract, $251 \pm 1.41$ $\mu \mathrm{g}$ tannic acid equivalent /mg of extract,117,4 $\pm 3,451 \mu \mathrm{g}$ quercetin equivalents/mg of extract, 139,5 $\pm 4,107 \mu \mathrm{g}$ rutin equivalents/mg of extract, respectively. In the DPPH assay, ethyl acetate extract showed the higher scavenging capacity ( $\mathrm{IC}_{50}=0.044 \pm 0.001 \mathrm{mg} / \mathrm{ml}$ ) followed by methanol, aqueous and chloroform extract. Whereas, AqE showed the best chelating effect and the best inhibitory capacity of the coupled oxidation of linoleic acid/ $\beta$-carotene.
\end{abstract}

Keywords: Ruta montana L; polyphenols; antioxidant activity; free radical scavenging.

\section{Article Info: Received 02 Jan 2020; $\quad$ Review Completed 18 Feb 2020; \\ Accepted 26 Feb 2020; \\ Available online 15 March 2020 \\ Cite this article as: \\ Merghem M, Dahamna D, In-Vitro Antioxidant Activity and Total Phenolic Content of Ruta montana L. Extracts, Journal of Drug Delivery and Therapeutics. 2020; 10(2):69-75 http://dx.doi.org/10.22270/jddt.v10i2.3919}

*Address for Correspondence:

Merghem Mounira, Laboratory of Phytotherapy Applied to Chronic Diseases, Department of biology and animal physiology, Faculty of Natural and Life Sciences, Ferhat Abbas University, Sétif, Algeria

\section{INTRODUCTION}

Free radicals are continuously produced by the body's normal use of oxygen such as respiration and some cell mediated immune function[1]. Oxygen is an element indispensable for life. When cells use oxygen to generate energy free radicals are produced by the mitochondria. These by-products are generally reactive oxygen species (ROS) as well as reactive nitrogen species (RNS) that result from the cellular redox process. The free radicals have a special affinity for lipids, proteins, carbohydrates and nucleic acids [2].
Some of these free radicals play a positive role in vivo such as energy production, phagocytosis, regulation of cell growth and intercellular signaling and synthesis of biologically important compounds [3]. At high concentrations, free radicals leads to damaging the lipids in the cell membranes, proteins in tissues as well as enzymes, carbohydrates, and DNA to induce oxidation. This oxidative damage may play a causative role in aging and several diseases which are cancer, cardiovascular disease, cataracts, and cognitive dysfunction [4]. 
Antioxidants are defined as any compounds or materials capable of delaying or preventing the oxidation of lipids, proteins, or other molecules by inhibiting initiation or propagation of free radical reaction [5]. Various compounds which have antioxidant activity have been isolated from plants, many of them are polyphenols including phenols, phenolic acids, flavonoids, tannins, and lignans [4].

Ruta species (Rutaceae) are sources of different classes of natural products such as flavonoids, alkaloids, essential oils, coumarins, phenols, saponins lignans, and triterpenes, with biological activities, including antifungal, antioxidant, phytotoxic, abortive depressant, antidotal and anti-inflammatory. Ruta montana in Arabic "fidjla", is a perennial aromatic herb originated from North Eastern Algeria. The plant has been used in Algeria as a cure for emmenagogue, antispasmodic and rubefiant [6].

The aim of the present study was the evaluation of the antioxidant activity of different extracts from the aerial part of Ruta montana L. using different in vitro tests and the total phenolic, flavonoids and tannins contents.

\section{MATERIALS AND METHODS}

\subsection{Chemicals}

Folin-Ciocalteu, aluminum chloride $\left(\mathrm{AlCl}_{3}\right)$, gallic acid, quercetin, rutin, 2,2-diphenyl-1-picrylhydrazyl hydrate (DPPH), ethylenediaminetetraacetic acid (EDTA), gallic acid and tween 40 were purchased from Sigma Chemical Co. (St. Louis, MO). Linoleic acid, $\beta$-carotene and butylated hydroxytoluene (BHT) were obtained from Fluka Chemical Co. (Buchs, Switzerland). Ferrous and ferric chloride were obtained from Merck. All other reagents were of analytical grade.

\subsection{Plant material}

Ruta montana L. was collected in October, from Beniaziz region, Wilaya of Sétif in Northeast of Algeria.

\subsection{Preparation of plant extract}

\subsubsection{Aqueous extract}

The aerial parts of plant material were cleaned with tap water, dried in the shade at room temperature for 2 weeks and ground into powder using an electric grinder. Briefly, 100g of Ruta montana L. powder was mixed with $1 \mathrm{~L}$ of boiled distilled water $\left(100^{\circ} \mathrm{C}\right)$ and was placed at room temperature during $72 \mathrm{~h}$, The resulting mixture was filtered using Wattman filter paper $\mathrm{n}^{\circ} 3$ and then evaporated in rotary vacuum evaporator at $45^{\circ} \mathrm{C}$

\subsubsection{Methanolic extract (Crude extract)}

The methanolic extract was obtained by maceration in water/methanol mixture (25:75) for $72 \mathrm{~h}$. The resultant extract was filtered through Wattman paper $n^{\circ} 3$ and the solvent was removed by rotary evaporator under reduced pressure at $45^{\circ} \mathrm{C}$. The resulting crude extract was then stored at $-20^{\circ} \mathrm{C}$ until further analysis [7].

\subsubsection{Fractionation of methanolic extract}

Fractionation of the crude extract is performed using a series of solvents of increasing polarity. The crude extract was initially mixed with the hexane $(\mathrm{V} / \mathrm{V})$ to eliminate lipids, and after separation, the upper organic phase was recovered. This step is repeated several times with renewal of the solvent until it becomes transparent. The hexane is then evaporated and the resulting extract is considered as the fraction of hexane. The lower aqueous phase was subjected to another fractionation with chloroform to give the chloroform extract (ChE), and finally by ethyl acetate to give the fraction of ethyl acetate (EAE). All fractions were preserved at $-20^{\circ} \mathrm{C}$ until use.

\subsection{Determination of total polyphenol content}

Total phenolic content was determined using Folin-Ciocalteu method, according to $\mathrm{Li}$ and $\mathrm{al}$, [8] with slight modifications. A volume of $100 \mu \mathrm{l}$ of the extract was mixed with $500 \mu \mathrm{l}$ of Folin-Ciocalteau (diluted 10\% in distilled water). After $4 \mathrm{~min}$, $400 \mu \mathrm{l}$ of sodium carbonate solution $\mathrm{Na}_{2} \mathrm{CO}_{3}(75 \mathrm{~g} / \mathrm{l}$ ) was added to the mixture, the reaction mixture was incubated at room temperature for $1 \mathrm{~h} 30 \mathrm{~min}$ and the absorbance of the mixture was measured at $760 \mathrm{~nm}$, Gallic acid (20-140 mg/l) was used as standard for the calibration curve. The total polyphenols content was expressed as micrograms of gallic acid equivalents (GAE) per milligram of extract. All samples were analyzed in three replications.

\subsection{Determination of total flavonoids contents}

The total flavonoids in plant extracts were determined using the aluminum trichloride $\left(\mathrm{AlCl}_{3}\right)$ method [9]. Briefly, $1 \mathrm{ml}$ of $2 \% \mathrm{AlCl}_{3}$ in methanol was mixed with $1 \mathrm{ml}$ of the extract. After incubation in dark at room temperature for $10 \mathrm{~min}$, the absorbance of the reaction mixture was measured at $430 \mathrm{~nm}$. Quercetin and rutin (1-40 mg/l) were used as standards for calibration curve and the total Flavonoids content was expressed as micrograms quercetin and rutin equivalents (QE 
and RE, respectively) per milligram of extract.

\subsection{Determination of tannins contents}

The test of haemoglobin precipitation by tannins compounds was used [10]. Briefly, a volume of each plant extract was mixed with an equal volume of heamolysed blood (absorbance $(576 \mathrm{~nm}$ ) = 1.6). After 20 minutes incubation, this mixture was centrifuged for 10 minutes at $4 \mathrm{C}$ and the absorbance of the supernatant was measured at $576 \mathrm{~nm}$. Different concentrations of tannic acid were also mixed with an equal volume of heamolysed blood and the absorbance was measured in the same manner. The tannins content was expressed as micrograms tannic acid equivalent per milligram of extract.

\subsection{Evaluation of antioxidant activity}

\subsubsection{DPPH free radical-scavenging assay}

The free radical scavenging activity of the extracts was measured by 2,2- diphenyl-1-picrylhydrazyl(DPPH) assay [11]. After dissolving the aqueous extract in distilled water, the methanol, chloroform and ethyl acetate extracts in methanol, the solution of DPPH in methanol $(0.04 \mathrm{mg} / \mathrm{mL})$ was prepared and $1250 \mu \mathrm{L}$ of this solution was added to $50 \mu \mathrm{L}$ of extracts solution at different concentration. The mixture was shaken vigorously and then kept in the dark for 30 minutes at room temperature. Then, the absorbance was measured at $517 \mathrm{~nm}$. BHT, rutin, quercetin and gallic acid were used as standards. All tests were performed in triplicate. Radical-scavenging activity was calculated using the following equation:

radical scavenging activity $(\%)=\left(\mathrm{A}\right.$ blank $-\mathrm{A}_{\text {sample }} / \mathrm{A}$ blank $) \times$ 100

A blank: Absorbance of the control.

A sample: Absorbance of the reagent with extract.

\subsection{2. $\beta$-carotene/linoleic acid assay}

In this test, the antioxidant capacity of the extracts was determined by measuring the inhibition of the oxidative degradation of $\beta$-carotene (discoloration or bleaching) by the oxidation products of the acid linoleic [12]. The $\beta$-carotene solution was prepared by dissolving $0.5 \mathrm{mg} \beta$-carotene in 1 $\mathrm{mL}$ of chloroform. One milliliter of this solution was pipetted to a flask covered with aluminum foil. Then $25 \mu \mathrm{L}$ of linoleic acid and $200 \mathrm{mg}$ of tween 40 were added. The chloroform was evaporated using evaporator at $45^{\circ} \mathrm{C}$. Then $100 \mathrm{~mL}$ of distilled water saturated with oxygen was added $2.5 \mathrm{~mL}$ of this prepared $\beta$-carotene solution were transferred to test tubes, and $350 \mu \mathrm{L}$ of the extracts $(2 \mathrm{mg} / \mathrm{mL}$ methanol) were added before incubation for $48 \mathrm{~h}$ at room temperature. The same procedure was repeated with butylated hydroxyl toluene (BHT) as a positive control and with distilled water and methanol as a negative control. The absorbance was reading at $490 \mathrm{~nm}$ after $1 \mathrm{~h}, 2 \mathrm{~h}, 6 \mathrm{~h}, 24 \mathrm{~h}$ and $48 \mathrm{~h}$. The antioxidant activity of extracts was calculated using the following equation:

$\mathrm{AA} \%=\mathrm{A}_{\text {sample }} / \mathrm{A}_{\text {BHT }} \times 100$.

A sample: Absorbance in the presence of the Extract; A внт: Absorbance in the presence of positive control BHT.

\subsubsection{Chelation of ferrous iron}

The chelating ability of the extracts is determined according to the method of Le and al, [13].which is based on the inhibition of the formation of $\mathrm{Fe}^{2+-}$-ferrosine complex after treatment of samples with $\mathrm{Fe}^{2+}$ ions. Briefly, $250 \mu \mathrm{L}$ of extract solutions at different concentrations were added to $50 \mu \mathrm{L}$ of $\mathrm{Fecl}_{2}(0.6 \mathrm{mM}$ in distilled water) and $450 \mu \mathrm{L}$ of methanol After 5 min of incubation, $50 \mu \mathrm{L}$ of ferrosine ( $5 \mathrm{mM}$ in methanol) was added, and the mixture was stirred and allowed to react for $10 \mathrm{~min}$ to allow the complexation of residual iron. The absorbance of the $\mathrm{Fe}^{2+}$-ferrosine complex was measured at $562 \mathrm{~nm}$ against a blank contained all the reaction reagents except ferrosine. Moreover, the negative control containing all reagents except that test sample is replaced by the same volume of methanol EDTA was used as reference chelator.

The chelating effect was calculated as a percentage, using the same equation as that in the DPPH assay.

\section{Statistical Analyses}

The results are expressed as the mean \pm standard deviation. One-way analysis of variance (ANOVA) followed by the Tukey test was performed to assess differences between groups. Differences were considered significant at $\mathrm{p}<0.05$.

\section{RESULTS AND DISCUSSION}

\subsection{Total polyphenols, flavonoids and tannins contents}

The contents of total polyphenols, flavonoids and tannins in extracts are shown in Table 1 . The results showed that EAE contain the highest amount of phenolic compounds $(257,1 \pm$ $0,703 \mu \mathrm{g} \mathrm{GAE} / \mathrm{mg})$, followed by $\mathrm{ChE}(245,6 \pm 6,005 \mu \mathrm{g}$ $\mathrm{GAE} / \mathrm{mg})$, CrE $(81,56 \pm 0,766 \mu \mathrm{g} \mathrm{GAE} / \mathrm{mg})$ and $\mathrm{AqE}(76,90 \pm$ $0,681 \mu \mathrm{g} \mathrm{GAE} / \mathrm{mg}$ ). 
Table 1. Total polyphenols, flavonoids and tannins content of Ruta montana L. extracts.

\begin{tabular}{|c|c|c|c|c|}
\hline \multirow[t]{2}{*}{ Extract } & \multirow{2}{*}{$\begin{array}{c}\text { Polyphenols } \\
\mu \mathrm{g} \text { GAE/mg extract }\end{array}$} & \multicolumn{2}{|c|}{ Flavonoids } & \multirow{2}{*}{$\begin{array}{c}\text { Tannins } \\
\mu \mathrm{g} \text { TAE/mg extract }\end{array}$} \\
\hline & & $\mu \mathrm{g} \mathrm{QE} / \mathrm{mg}$ extract & $\mu \mathrm{g} \mathrm{RE} / \mathrm{mg}$ extract & \\
\hline $\mathrm{CrE}$ & $81,56 \pm 0,766$ & $50,80 \pm 1,247$ & $60,10 \pm 1,484$ & $80.33 \pm 0.70$ \\
\hline ChE & $245,6 \pm 6,005$ & $35,81 \pm 1,118$ & $42,23 \pm 1,330$ & $83 \pm 0.98$ \\
\hline EAE & $257,1 \pm 0,703$ & $117,4 \pm 3,451$ & $139,5 \pm 4,107$ & $251 \pm 1.41$ \\
\hline $\mathrm{AqE}$ & $76,90 \pm 0,681$ & $22,54 \pm 0,2205$ & $26,54 \pm 0,3002$ & $33.6 \pm 0.84$ \\
\hline
\end{tabular}

CrE; methanolic extract, ChE; chloroform extract, EAE; ethyl acetate extract, AqE; aqueous extract; GAE: gallic acid equivalent; QE: quercetin equivalent ; RE: rutin equivalent ; TAE: tannic acid equivalent. Each value represents the mean $\pm \operatorname{SD}(n=3)$.

The highest value of flavonoids found in EAE was $117,40 \pm$ $3,45 \mu \mathrm{g} \mathrm{QE} / \mathrm{mg}, 139,5 \pm 4,11 \mu \mathrm{g} \mathrm{RE} / \mathrm{mg}$ and the lowest was $22,54 \pm 0,22 \mu \mathrm{g} \mathrm{QE} / \mathrm{mg}, 26,54 \pm 0,30 \mu \mathrm{g} \mathrm{RE} / \mathrm{mg}$ for AqE with the following decreasing order: $\mathrm{EAE}>\mathrm{CrE}>\mathrm{ChE}>\mathrm{AqE}$. On the other hand, EAE contained the highest amount of tannins $(251 \pm 1.41 \mu \mathrm{g} \mathrm{TAE} / \mathrm{mg} \mathrm{E})$, followed by ChE $(83 \pm 0.98 \mu \mathrm{g}$ $\mathrm{TAE} / \mathrm{mg} \mathrm{E}), \mathrm{CrE}(80.33 \pm 0.70 \mu \mathrm{g} \mathrm{TAE} / \mathrm{mg} \mathrm{E})$ and the AqE (33.6 $\pm 0.84 \mu \mathrm{g} \mathrm{TAE} / \mathrm{mg} \mathrm{E})$.

\subsection{Antioxidant activity evaluation}

\subsubsection{DPPH radical scavenging activity}

The scavenging ability of the extracts was expressed as $\mathrm{IC}_{50}$ value, which is the concentration of substrate that causes $50 \%$ loss of DPPH activity (color) [14]. Low $\mathrm{IC}_{50}$ value indicates strong ability of the extract to act as DPPH scavenger. The DPPH scavenging activity of the extracts is represented in table 2 . The results revealed that the EAE exhibited the highest radical scavenging activity with $\mathrm{IC}_{50}$ of $(0.044 \pm 0.001 \mathrm{mg} / \mathrm{ml})$, which was significantly near to that of BHT $(0.032 \pm 0.000 \mathrm{mg} / \mathrm{ml})$, followed by $\mathrm{CrE}$ with $0.067 \pm$ $0.002 \mathrm{mg} / \mathrm{ml}$, AqE with $0.083 \pm 0.003 \mathrm{mg} / \mathrm{ml}$ and $\mathrm{ChE}$ with $0.146 \pm 0.015 \mathrm{mg} / \mathrm{ml}$

Table 2: DPPH scavenging activity of Ruta montana L. extracts and standards.

\begin{tabular}{cccc}
\hline Standards & $\mathrm{IC}_{50}(\mathrm{mg} / \mathrm{mL})$ & Extracts & $\mathrm{IC}_{50}(\mathrm{mg} / \mathrm{mL})$ \\
\hline BHT & $0.032 \pm 0.000$ & $\mathrm{CrE}$ & $0.067 \pm 0.002^{* *}$ \\
Gallic acid & $0.056 \pm 0.001^{\#}$ & $\mathrm{ChE}$ & $0.146 \pm 0.015^{* * *}$ \\
Quercetin & $3.491 \pm 0.001^{\#}$ & EAE & $0.044 \pm 0.001^{\mathrm{ns}}$ \\
Rutin & $4.179 \pm 0.000^{\#}$ & AqE & $0.083 \pm 0.003^{* * *}$ \\
\hline
\end{tabular}

\#: $\mu \mathrm{g} / \mathrm{ml}$. Comparison was realized against BHT, ${ }^{* *}: \mathrm{p} \leq 0.01,{ }^{* *}: \mathrm{p} \leq 0.001$. Each value represents the mean $\pm \operatorname{SD}(\mathrm{n}=3)$.

\subsection{2. $\beta$-carotene/linoleic acid bleaching assay}

As can be seen in figure 1 and figure 2, all the extracts were capable of inhibiting the bleaching of $\beta$-carotene by scavenging linoleate derived free radicals.
AqE and ChE exhibited the highest antioxidant activity $(90.34$ $\pm 0.46 \%$ and $89.92 \pm 0.29 \%$, respectively), which was near to that of BHT ( $100 \pm 0.52 \%$ ), following by EAE and CrE with an antioxidant activity $(73.56 \pm 0.63 \%$ and $63.27 \pm 2.27 \%$, respectively). 


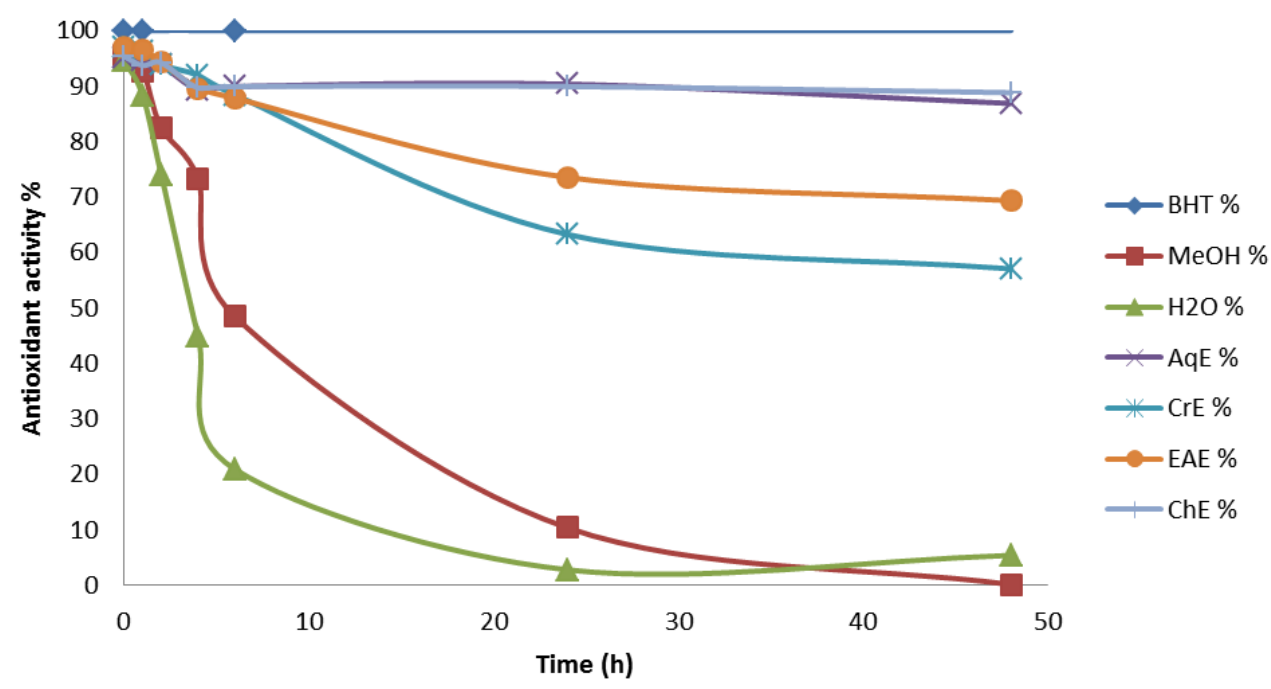

Fig.1. The changes in the percentage of the inhibition ratios of linoleic acid oxidation under the influence of Ruta montana L. extracts (2mg/mL), compared to BHT as a positive control during $48 \mathrm{~h}$. AqE: aqueous extract, CrE: crude extract, ChE: chloroform extract, EAE: ethyl acetate extract.

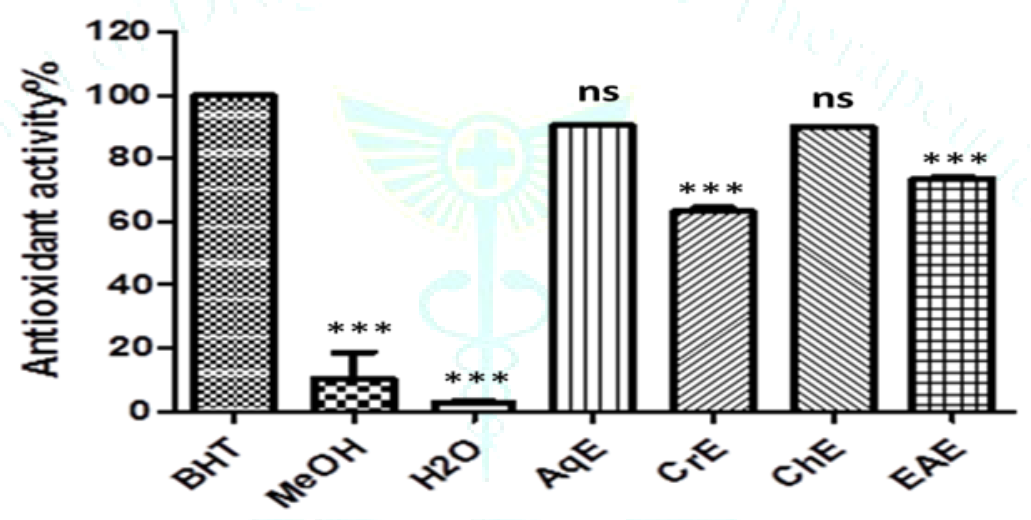

Fig.2. Inhibition percentage of extracts of Ruta montana L. in $\beta$-carotene/linoleic acid assay after $48 \mathrm{~h}$ compared with BHT, methanol and water as standards. Results represent the means $\pm \mathrm{SD}(\mathrm{n}=3)$. High inhibition percentage indicates higher antioxidant activity. AqE: aqueous extract, CrE: crude extract, ChE: chloroform extract, EAE: ethyl acetate extract.

\subsubsection{Metal chelating activity}

Table 3 list IC50 values of Ruta montana L. extracts obtained from measurement of metal chelating activity. The smaller $\mathrm{IC}_{50}$ value represents the higher metal chelating activity. The
AqE and CrE appear to have the most important chelating activity with $\mathrm{IC}_{50}$ values of $0.005 \pm 0.004 \mathrm{mg} / \mathrm{ml}$ and $0.021 \pm$ $0.005 \mathrm{mg} / \mathrm{ml}$, respectively. The chelating effect of $\mathrm{ChE}$ and EAE is very low $\left(\mathrm{IC}_{50}=0.146 \pm 0.015\right.$ and $0.771 \pm 0.021 \mathrm{mg} /$ $\mathrm{ml}$, respectively).

Table 3. Metal chelating activity of Ruta montana L. extracts and EDTA.

\begin{tabular}{cc}
\hline Extracts & $\mathrm{IC}_{50}(\mathrm{mg} / \mathrm{ml})$ \\
\hline CrE & $0.021 \pm 0.005^{\mathrm{ns}}$ \\
ChE & $0.146 \pm 0.015^{* * *}$ \\
EAE & $0.771 \pm 0.021^{* * *}$ \\
AqE & $0.005 \pm 0.004^{\mathrm{ns}}$ \\
EDTA & $5.32 \pm 0.03^{\#}$ \\
\hline
\end{tabular}

$\#: \mu \mathrm{g} / \mathrm{mL}$. Comparison was realized against EDTA; ${ }^{* * *}: \mathrm{p} \leq 0.001$. Each value represents the mean $\pm \operatorname{SD}(\mathrm{n}=3)$. 
Plant phenolics, tannins and flavonoids represent major groups of plant constituents that work predominantly as powerful antioxidants or scavenger of free radicals. They play beneficial role in human health and cure or prevent ailments such as inflammatory disorders, cardiovascular diseases, cancer and diabetes which occur due to the deregulation of free radicals generation in the cells [15].

There have been two opinions on the correlation between phenolics and total antioxidant activity. Some reports demonstrated positive correlation between them [16,17] and the others showed no correlation [18]. Our results agree with the latter, it seems that no correlation exists either between the percentage inhibition (\% scavenging effect) assayed by DPPH and total phenolics, between the antioxidant activity assayed by $\beta$ - carotene blenching method and total phenolics, or between the antioxidant activity assayed by ferrous ion chelating ability and total phenolics. [19] thought this phenomenon can be explained on the basis of high antioxidant activity of some individual phenolic units, which may act as efficient antioxidants rather than contributing to high total phenolics, while [20] thought that total phenolics content did not include all the antioxidants, such as ascorbic acid, carotenoid and tocopherol. [21] held the idea that the synergism among the antioxidants in the mixture made the antioxidant activity not only dependent on the concentration of antioxidant, but also on the structure and interaction among the antioxidants. This probably is the reason why samples with similar concentrations of total phenolics may vary remarkably in their antioxidant activity.

In general the antioxidant activity of phenolic compounds reportedly varies with the structure and degree of hydroxylation of the aromatic ring $[22,23]$. It is associated with the number of hydroxyl groups and the most active possess from 3 to 6 hydroxyl groups. Hydroxylation in the C3 position seems to be detrimental for their antioxidant potency [24]. [25] reported that for benzoic and cinnamic acid derivatives, flavonols and anthocyanidins, an increase in the number of hydroxyl groups on the aromatic ring lead to higher antioxidant activity in vitro. Compounds with three hydroxyl groups on the phenyl ring of phenolic acids or the B-ring of flavonoids had high antioxidant activity. The loss of one hydroxyl group decreased activity slightly.

3' 4' ortho dihydroxy configuration (catechol) in B ring and 3-OH group in $\mathrm{C}$ ring is very important for antiradical efficacy. Catechol ring and C2 - C3 double bond conjugated with 4- keto moiety are essential for electron delocalization from the ring $B$, and it increases the antiradical activity [26]. Many studies showed that when these structural features were removed from flavonoids structure their antioxidant activity was decreased $[27,28]$.

\section{CONCLUSION}

The present study aimed to evaluate the Antioxidant activity of extracts prepared from the aerial parts of Ruta montana L. , this activity was tested in vitro using three methods : DPPH (2, 2'-diphenyl- 1- picrylhydrazy), bleaching of $\beta$-carotene and chelation of ferrous iron. The results showed that Ruta montana L. has an important antioxidant activity. The ethyl acetate extract exhibited the highest scavenging activity, whereas aqueous extract showed the best chelating capacity and the best inhibitory capacity of the coupled oxidation system of linoleic acid/ $\beta$-carotene.

\section{ACKNOWLEDGEMENTS}

This work was supported by the Algerian Ministry of Higher Education and Scientific Research (MERS) and by the Algerian Agency for the Development of Research in Health (ANDRS). We express our gratitude to these organizations.

\section{REFERENCES}

[1] Saâdane H, Ennachete M, Moutcine A, Qouatli ElS and Chtaini A. New Electrodes Based on Garlic for the Inhibition of the Free Radicals Effects. Pharm Anal Acta., 2017, 8-11.

[2] Sisein E.A. Biochemistry of Free Radicals and Antioxidants. Sch. Acad. J. Biosci., 2014, 2(2), 110-118

[3] Beris H. Antioxidant effects a basis of drug selection. Drugs 1991; 42: 569-605.

[4] Rusmana D, Wahyudianingsih R, Elisabeth M, Maesaroh B, Widowati W. Antioxidant Activity of Phyllanthus niruri Extract, Rutin and Quercetin. Indones Biomed J., 2017, 9(2), 84-90.

[5] Herlina N, Riyanto S, Martono S and Abdul Rohman. Antioxidant Activities, Phenolic and Flavonoid Contents of Methanolic Extract of Stelechocarpus burahol Fruit and its Fractions. Dhaka Univ. J. Pharm. Sci., 2018, 17(2), 153-159.

[6] Kara Ali W, Ihoual S and Abidli N. Antioxidant and MDR reversal activity in resistant human ovarian cancer cells of methanolic extract from Ruta Montana located in the North of Algeria, Der Pharma Chemica., 2016, 8(12), 215-223.

[7] Sunday 00, Uguru OM. Peripheral and central antinociceptive activities of the crude methanolic extract and fractions of Momordicabalsaminalinn. Asian Journal of Pharmaceutical and Clinical Research., 2010, 0974-2441. 
[8] Li HB, Cheng KW, Wong CC, Fan KW, Chen F, Jiang Y. Evaluation of antioxidant capacity and total phenolic content of different fractions of selected microalgae. Food Chemistry., 2007, 102, 771-776.

[9] Bahorun T, Gressier B, Trotin F, Brunete C, Dine T, Vasseur J, Gazin JC, Pinkas M, Luycky M, Gazin M. Oxygen species scavenging activity of phenolic extract from Hawthorn fresh plant organs and pharmaceutical preparation. Drug Research., 1996; 16.

[10] Bate-Smith EC. Haemanalysis of tannins, the concept of relativeastringency. Phytochemistry., 1973, 12, 907-12.

[11] Burits M, Bucar F. Antioxidant activity of Nigella sativa essential oil. Phytotherapy Research., 2000, 14, 323-328.

[12] Kartal N, Sokmen M, Tepe B, Daferera D, Polissiou M, Sokmen A. Investigation of the antioxidant properties of Ferula orientalis L. using a suitable extraction procedure. Food chemistry., 2007, 100, 584-589.

[13] Le K, Chiu F, Ng K. Identification and quantification of antioxidants in Fructus lycii. Food Chemistry., 2007, 105, 353-363.

[14] Molyneux P. The use of the stable free radical diphenylpicrylhydrazyl (DPPH) for estimating antioxidant activity. Songklanakarin J Sci Technol., 2004, 26 (2), 211-219.

[15] Chouhan HS, Singh SK. Phytochemical analysis, antioxidant and anti-inflammatory activities of Phyllanthus simplex. J of Ethnopharmacology., 2011, 137, 1337-1344.

[16] Wangensteen H, Samuelsen AB, Maltrud KE. Antioxidant activity in extracts from coriander. Food Chem., 2004, 88, 293-297.

[17] Zielinski H, Kozlowska H. Antioxidant activity and total phenolics in selected cereal grains and their different morphological fractions. J Agric Food Chem., 2000, 48, 2008-2016.

[18] Sun T, Ho CT. Antioxidant activities of buckwheat extracts. Food Chem., 2005, 90, 743-749.

[19] Kaur C, Kapoor HC. Anti-oxidant activity and total phenolic content of some Asian vegetables. Inter J Food SciTech., 2002, $37,153-161$.

[20] Kähkonen MP, Hopia AI, Heinonen M. Berry phenolics and their antioxidative activity. J. Agric. Food Chem., 2001, 49, 4076-4082.

[21] Vinson JA, Su XH, Zubik L, Bose P. Phenol antioxidant quantity and quality in foods: Fruits. J Agric Food Chem., 2001, 49, 5315-5321.

[22] Burda S, Oleszek W. Antioxidant and antiradical activities of flavonoids. Journal of Agricultural and Food Chemistry., 2001, 49, 2774 - 2779.

[23] Aruoma O I. Methodological considerations for characterizing potential antioxidantactions of bioactive components in plant foods. Mutation Research., 2002, 9 (20), 523-524.

[24] Huguet AI, Manez S, Alcaraz MJ. Superoxide scavenging properties of flavonoids in a non-enzymic system. Z. Naturforsch $1990,45,19-24$

[25] Fukumoto L R, Mazza G. Assessing antioxidant and prooxidant activities of phenolic compounds. Journal of Agricultural and Food Chemistry., 2000, 48, 3597 - 3604.

[26] Sharififar F, Nudeh G D, Mitrajaldini M. Major flavanoids with antioxidant activity from Teucrium polium L. Food Chem., 2009, 112, 885-888.

[27] Silva MM, Santos MR, Caroco G, Rocha R, Justiuo G, Mira L. Structure antioxidant activity relationships of flavonoids: A -Re-examination. Free radical Research., 2002, 36(11), 1219-1227.

[28] Furusawa M, Tanaka T, Ito T, Nishikawa A, amazaki NY, Nakaya K, Matsuura N, Tsuchiya H, Iinuma M. Antioxidant activity of hydroxyl flavonoids. J Health Sci., 2005, 51(3), 376-378. 